\title{
Central Neurocytomas: A Comprehensive Review with Special Emphasis on the Role of Gamma Knife Stereotactic Radiosurgery
}

Nandish Hodaghatta Shivaramegowda ${ }^{1}$, Sachin Anil Borkar ${ }^{1 *}$, Kanwaljeet Garg ${ }^{1}$, Vaishali Suri ${ }^{2}$, Mehar Chand Sharma ${ }^{2}$, Bhawani Shankar Sharma ${ }^{1}$ and Ashok Kumar Mahapatra ${ }^{3}$

${ }^{1}$ Department of Neurosurgery, All India Institute of Medical Sciences, New Delhi, India

${ }^{2}$ Department of Pathology, All India Institute of Medical Sciences, New Delhi, India

${ }^{3}$ Director, All India Institute of Medical Sciences, Bhubaneshwar, India

"Corresponding author: Dr. Sachin Anil Borkar, Room No 720, Department of Neurosurgery, Cardio-Neuro Centre, All India institute of Medical Sciences, New Delhi, India, Tel: +919968959645; Fax: +91-11-26583832; E-mail: sachin.aiims@gmail.com

Received date: July 21, 2014, Accepted date: August 01, 2014, Published date: August 20, 2014

Copyright: (C) 2014 Shivaramegowda NH, et al. This is an open-access article distributed under the terms of the Creative Commons Attribution License, which permits unrestricted use, distribution, and reproduction in any medium, provided the original author and source are credited.

\begin{abstract}
Central Neurocytomas (CNs) are uncommon tumors of central nervous system, arising from neuronal cells. Mostly these tumors are intraventricular and commonly occurs at the level of the "Foramen of Monro". However, recently cases of "Extraventricular Neurocytoma" have also been reported. Typically, CNs are associated with favorable outcome. Best long term prognosis, in terms of local control and survival is achieved by maximal safe surgical resection, which is considered as ideal therapeutic option. However, management of recurrent or residual $\mathrm{CNs}$ remains controversial. Treatment options for patients with recurrent or residual CNs includes reoperation, radiotherapy or chemotherapy. Use of conventional radiotherapy in recurrent or residual CNs is associated with long term complications in the form of cognitive abnormalities and risk of developing secondary malignancies. Recently, Gamma Knife Radiosurgery is used in patients with recurrent or residual CNs as an alternative treatment option to conventional radiotherapy. Studies have reported that Gamma Knife Radiosurgery provides safe and effective alternative treatment option for recurrent or residual $\mathrm{CNs}$, by eliminating the long term side effects of conventional radiotherapy. However, these are based on results of limited number of studies, with small sample sizes, with no control groups. Randomized control trials or larger studies are required to confirm the effectiveness of Gamma knife Radiosurgery in recurrent or residual CNs. This paper reviews the findings of case series and case reports that contribute to the effectiveness of Gamma knife Radiosurgery in CNs.
\end{abstract}

Keywords: Central neurocytoma; Treatment; Gamma knife

\section{Introduction}

Central neurocytomas $(\mathrm{CNs})$ are unusual tumors of the central nervous system, characterized by midline intraventricular location particularly at the level of "Foramen of Monro" [1]. It was first described by Hassoun et al. [2], in 1982, who reported two cases of Central neurocytomas and defined these tumors as a different pathological entity. In 1993, Hassoun et al. [2], reviewed the literature of 127 cases of $\mathrm{CNs}$ and summarized the epidemiology, clinical presentation and histopathological features. Since the original description by Hassoun et al. [2], there has been a steady increase in recognition of this entity. However, despite their increased recognition, CNs remain rare neoplasms of the central nervous system. Generally, the incidence of this tumor is only $0.25-0.5 \%$ of all brain tumors $[2,3]$.

\section{Epidemiology and Clinical Presentation}

CNs predominantly occurs in young adults (between the ages of 20 and 40 years), with a mean age at presentation being 29 years,with no clear preponderance of either sex [2]. Largely CNs are midline lesions spanning the lateral and third ventricles, often in relation to the "Foramen of Monro" and arising from the neuronal cells of septum pellucidum, fornix, or walls of the lateral ventricles [2]. Patients typically present with signs and symptoms of obstructive hydrocephalus in the second and third decades of life [3]. Schild et al. [3], in his study of 27 patients withCNs regarding the presenting symptoms, most of the symptoms were attributed to increased intracranial pressure secondary to obstructive hydrocephalus, found that $93 \%$ of patients had headache, $37 \%$ had visual changes, and $30 \%$ had nausea and vomiting. Less frequently, patients complained of lethargy (11\%), balance problems (11\%), and tinnitus (7\%) [3].

\section{Imaging}

Typical imaging features of central neurocytomasare as follows [4], plain Computed Tomography scan shows an iso to slightly hyperdense mass in the lateral ventricle with moderate postcontrast enhancement with hypodense areas corresponding to cystic degeneration. On CT 50\% demonstrate calcification and evidence of obstructive hydrocephalus. Magnetic resonance imaging shows an inhomogeneous mass, isointense on T1 weighted image, isointense or hyperintense on T2 weighted image with moderate to strong postcontrast enhancement (Figures 1-3). 
Citation: Shivaramegowda NH, Borkar SA, Garg K, Suri V, Sharma MC, et al. (2014) Central Neurocytomas: A Comprehensive Review with Special Emphasis on the Role of Gamma Knife Stereotactic Radiosurgery. J Hematol Thrombo Dis 3: 140. doi:10.4172/2168-975X. 1000140

Page 2 of 5

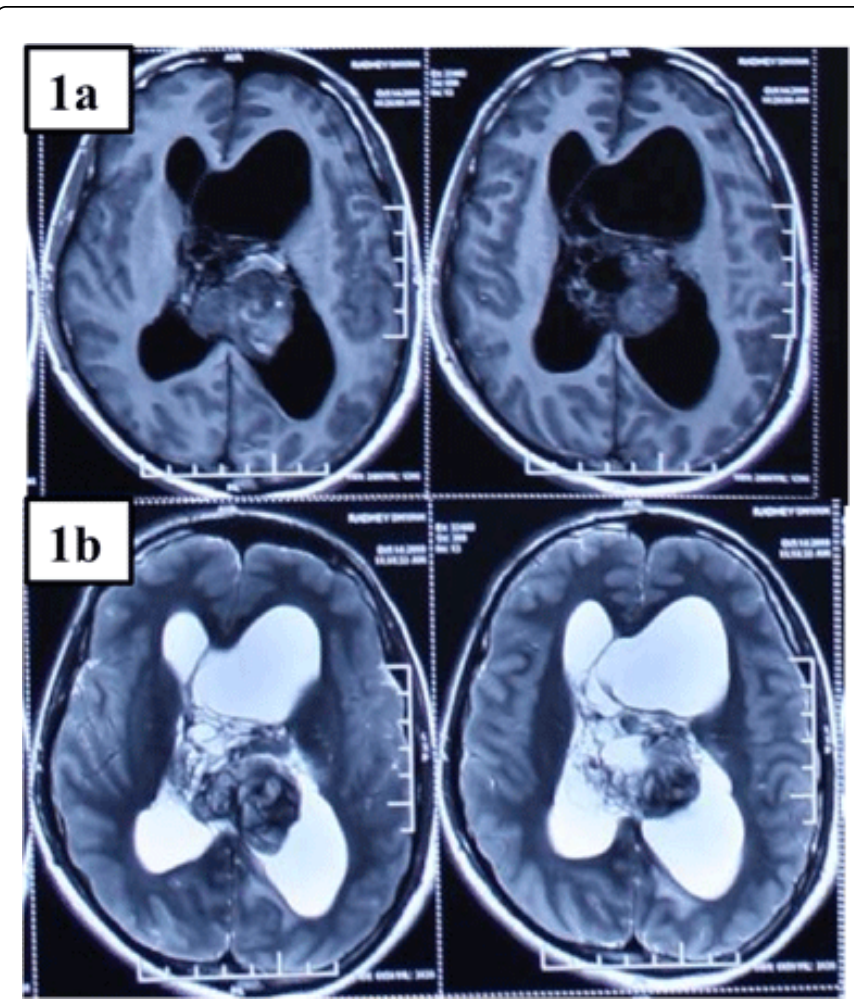

Figure 1: T1 and T2 weighted MRI axial sections showing a large hypo to isointense intraventricular lesion extending into both lateral ventricles with ventriculomegaly.

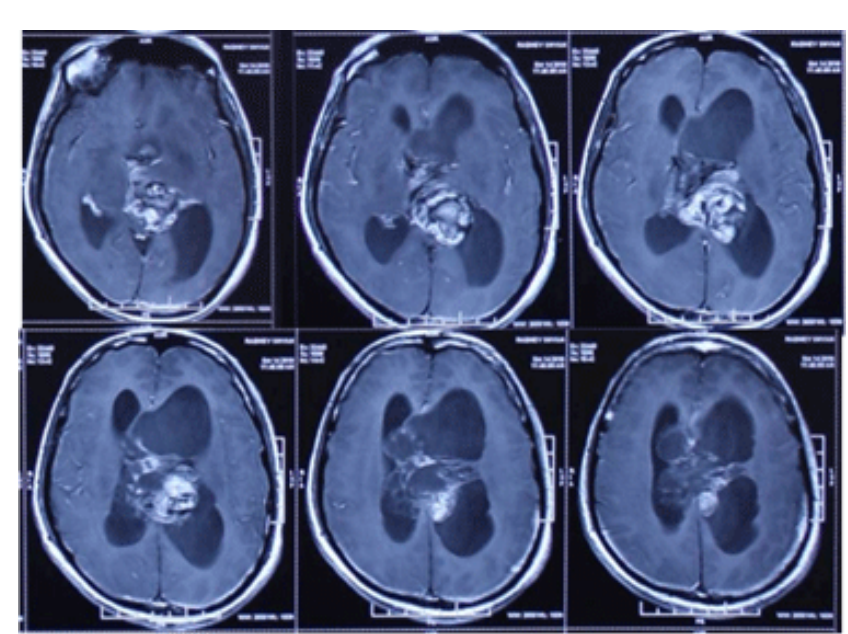

Figure 2: Post contrast axial sections showing heterogenous contrast enhancement in the intraventricular lesion located in the lateral ventricles

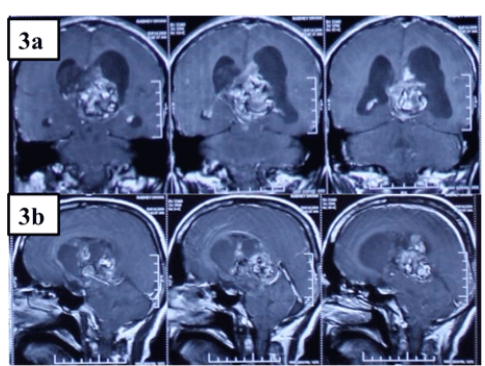

Figure 3: Post contrast coronal (a) and sagittal (b) sections showing the heterogenusly enhancing intraventricular lesion

\section{Neuropathology}

Grossly Neurocytomas are generally greyish in color, well circumscribed, lobulated, resembling the grey matter, with areas of hemorrhage and cystic degeneration and calcifications [5]. On light microscopy these tumors are composed of uniform, small-to-mediumsized cells with rounded nuclei, finely stippled chromatin ("salt and pepper" chromatin) and inconspicuous nucleoli, along with scant cytoplasm, resembling "fried-egg" appearance of oligodendroglioma [5]. On electron microscopy these tumors shows high degree of neuronal differentiation containing parallel arrays of microtubules, with both clear core vesicles and dense core granulations in their terminations. Though intermediate filaments and synapse formation are seen, but these are not essential for diagnosis [5]. On immunohistochemistry vast majority of neurocytomas have been diagnosed on the basis of synaptophysin immunoreactivity alone, even without ultrastructural evaluation [5]. Strong immunostaining for synaptophysin has been recognized as the most appropriate and consistent diagnostic marker (Figure 4). CNs also shows positivity for Neuron specific enolase, however, positivity of Glial fibrillary acidic protein (GFAP) is variable [5].

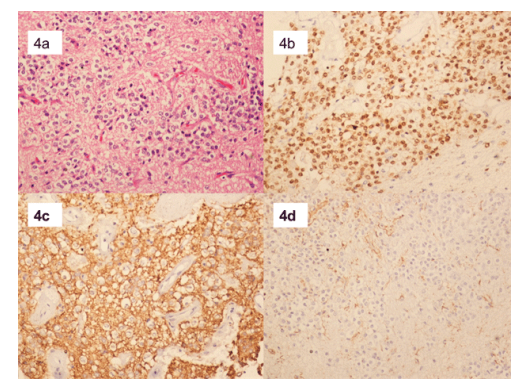

Figure 4: Photomicrograph showing monophasic population of oligodendroglia like celss in a fibrillary background $(a, H \& E \times 200)$, immunohistochemistry staining for NEU N1 and synaptophysin showing diffuse positivity $(\mathrm{b}$ and $\mathrm{c}, \times 200)$, the cells are immunonegative for GFAP (d, H\&E×200)

\section{Treatment Options, Strategies and Outcome}

Many clinical studies show that gross total resection (GTR) confers long term control for the CNs [3,6,7]. Schild et al. [3], analysed 32 patients with CNs retrospectively with a median follow up of $4.7 \mathrm{yrs}$ 
Citation: Shivaramegowda NH, Borkar SA, Garg K, Suri V, Sharma MC, et al. (2014) Central Neurocytomas: A Comprehensive Review with Special Emphasis on the Role of Gamma Knife Stereotactic Radiosurgery. J Hematol Thrombo Dis 3: 140. doi:10.4172/2168-975X. 1000140

Page 3 of 5

and reported a 5-year local control and survival rate of $100 \%$ and $80 \%$ after GTR, without adjuvant therapy. The 5-year local control rate was $70 \%$ for patients undergoing subtotal resection (STR). The 5-year local control rate was $100 \%$ for patients who received RT after STR compared with $50 \%$ for those who did not. Kim et al. [6], retrospectively analyzed 15 cases of central neurocytoma, over a period of $13 \mathrm{yrs}$, with a median follow up of 52 months and showed that 2 out of 5 patients with GTR without RT recurred, two patients with GTR and RT remained stable, three patients with STR without RT were stable, five patients with STR and RT were stable. They concluded that radiotherapy appeared to have an effect on tumor control and reduce the chances of recurrence. Various studies quoting the use of primary and secondary Gamma Knife Radiosurgery in central neurocytoma have been summarized in Table 1.

\begin{tabular}{|c|c|c|c|c|c|c|c|c|c|}
\hline Authors & $\begin{array}{l}\text { No. of } \\
\text { pts }\end{array}$ & $\begin{array}{l}\text { GK as primary or } \\
\text { secondary }\end{array}$ & $\begin{array}{l}\text { Dose of } \\
\text { GK,Gy }\end{array}$ & $\begin{array}{l}\text { Follow up } \\
\text { period } \\
\text { (months) }\end{array}$ & $\begin{array}{l}\text { Pre-GK } \\
\text { tumor } \\
\text { volume, } \\
\mathrm{ml}\end{array}$ & $\begin{array}{l}\text { Post GK tumor } \\
\text { volume, } \mathrm{ml}\end{array}$ & $\begin{array}{l}\text { Clinical } \\
\text { outcome }\end{array}$ & Recurrence & Complication \\
\hline Schild et al. [3] & 1 & NA & 15 & - & NA & $\begin{array}{l}\text { No change at } 13 \\
\text { months }\end{array}$ & - & - & - \\
\hline $\begin{array}{l}\text { Pollock et al. } \\
{[21]}\end{array}$ & 1 & Secondary (recurrent) & 18 & 34 & 2.7 & Reduced & Good & No & None \\
\hline \multirow{3}{*}{$\begin{array}{l}\text { Bertalanffy et } \\
\text { al. [8] }\end{array}$} & \multirow[t]{3}{*}{3} & \multirow[t]{3}{*}{ Secondary (recurrent) } & \multirow[t]{3}{*}{$9.6-19$} & \multirow[t]{3}{*}{$12-60$} & 0.6 & 0.25 & Good & No & None \\
\hline & & & & & 5.9 & 2.3 & Good & No & None \\
\hline & & & & & 5.2 & 3.1 & Good & No & None \\
\hline $\begin{array}{l}\text { Anderson et } \\
\text { al. [14] }\end{array}$ & 4 & Secondary(recurrent) & $16-20$ & $12-28$ & $1.7-12.3$ & Reduced & Good & No & None \\
\hline \multirow{4}{*}{$\begin{array}{l}\text { Cobery et al. } \\
{[17]}\end{array}$} & \multirow[t]{4}{*}{4} & \multirow{4}{*}{$\begin{array}{l}\text { Residual-3 } \\
\text { Recurrent-1 }\end{array}$} & \multirow[t]{4}{*}{$9-13$} & \multirow[t]{4}{*}{$12-99$} & 6.5 & 3.5 & Good & No & None \\
\hline & & & & & 13 & 3.6 & Good & No & None \\
\hline & & & & & 29 & 5.4 & Good & No & None \\
\hline & & & & & 10.5 & 2.5 & Good & No & None \\
\hline \multirow[t]{4}{*}{$\begin{array}{l}\text { Tyler-kabara } \\
\text { et al. [16] }\end{array}$} & \multirow[t]{4}{*}{4} & \multirow{4}{*}{$\begin{array}{l}\text { Primary-2 } \\
\text { Residual-1 } \\
\text { Recurrent-1 }\end{array}$} & \multirow[t]{4}{*}{$14-20$} & \multirow[t]{4}{*}{$38-53$} & 7.9 & $\begin{array}{l}\text { Reduced } \\
\text { significantly }\end{array}$ & Good & No & None \\
\hline & & & & & 4.2 & & & & \\
\hline & & & & & 0.33 & & & & \\
\hline & & & & & 1.3 & & & & \\
\hline Hara et al. [18] & 1 & Residual & 20 & 12 & 5.7 & $\begin{array}{l}80 \% \text { reduction at } \\
2 \text { months }\end{array}$ & Good & No & None \\
\hline Kim et al. [15] & 13 & $\begin{array}{l}\text { Residual-7 } \\
\text { Primary-6 }\end{array}$ & $9-20$ & $6-96$ & $4.6-36.4$ & $0.4-12.1$ & Good & No & None \\
\hline $\begin{array}{l}\text { Ali Genc et al. } \\
\text { [19] }\end{array}$ & 22 & Residual \& recurrent & 16.4 & 36.7 & $0.7-68.9$ & $\begin{array}{l}\text { 6-unchanged } \\
15 \text {-decrease in } \\
\text { size } \\
1 \text {-increased in } \\
\text { size }\end{array}$ & Good & No & None \\
\hline TOTAL & 53 & Primary-8, secondary- 45 & & & & & & & \\
\hline
\end{tabular}

Table 1: Summary of reports for Central Neurocytoma treated with Gamma Knife Radiosurgery

Leenstra et al. [7], retrospectively analysed 45 patients with CNs with a median follow-up was 10.0 years showed that the 10 -year overall survival and local control rate was $83 \%$ and $60 \%$, respectively. Patients whose tumor had a mitotic index of $<3$ (per 10 high-power fields) experienced a 10-year survival and local control rate of $89 \%$ and $74 \%$, respectively, compared with $57 \%(\mathrm{p}=0.040)$ and $46 \%(\mathrm{p}=0.14)$ for patients with a tumor mitotic index of $\geq 3$. The 10 -year survival and local control rate was $90 \%$ and $74 \%$ for patients with typical tumors compared with 63\% $(\mathrm{p}=0.055)$ and $46 \%(\mathrm{p}=0.41)$ for those with atypical tumors. A comparison of gross total resection with subtotal resection showed no significant difference in survival or local control. Postoperative RT improved local control at 10 years ( $75 \%$ with RT vs. $51 \%$ without RT, $\mathrm{p}=0.045$ ); however, this did not translate into a survival benefit. 
Bertalanffy et al. [8], retrospectively analysed 14 patients over a period of 17 years and out of the 14, 2 patients (14\%) died postoperatively and one patient had a malignant course (7\%). In the remaining 11 patients, one patient with an incompletely resected $\mathrm{CN}$ had disease progression after 37 months but at the time of last followup had had a stable disease for 10 years. In addition, the authors reported 5 patients with disease recurrence, occurring at a median gap of 67 months after surgery (range, 51-79 months after surgery), all of which occurred after complete surgical resection was performed and concluded that, CNs appear to have a higher tendency to recur during long-term follow-up than previously reported, even after complete resection. Chemotherapy can be useful for recurrent or residual CNs that cannot be resected and have been irradiated, but long term responses have not been reported regarding the use of chemotherapy [9-11]

Paek et al. [12], reported the long-term outcome following conventional radiation therapy (RT) in six cases of CNs. Between 1985 and 1992, six patients were treated with RT for residual tumors or for prevention of recurrence after surgery. The median follow-up period of radiological and clinical status were 171 (range: 128-229) and 202 months (range: 165-227), respectively. Tumors disappeared in three and reduced in three patients at the last follow-up. One mortality occurred due to radiation necrosis and another with radiation induced malignancy occurred. White matter degeneration and cortical atrophy were noticed with slow progression of performance deterioration in two patients. They concluded that conventional RT seemed to effectively control residual CNs after surgery. However, more sophisticated radiation techniques should be applied to minimize the long term sequelae of radiation therapy.

Rades et al. [13], reviewed 121 patients with CNs over a period of 8 years and concluded that the results of both conventional radiotherapy and sterotactic radiosurgery (SRS) were similar, however, SRS is a reasonable alternative to conventional therapy in selected patients. Since most neurocytomas are located close to the fornix, septum pellucidum, corpus callosum and litle is known about the radiation tolerance of these structures, therefore use of conventional radiotherapy has been criticized because of well known long term side effects on cognitive function and also development of secondary malignancies. Stereotactic radiosurgery potentially avoids these side effects with its rapid dose fall off effect at the target edges and local control of tumor growth [14].

There are a few case reports and small case series indicating the effectiveness of stereotactic radiosurgery treatments for residual neurocytomas with similar results as conventional radiotherapy but without any serious side effects. Kim et al. [15] reported complete disappearance of tumor mass at 36 months and no side effects after LINAC based.

SRS. Tyler-Kabara et al. [16] reported four patients in their case series who underwent gamma-knife radiosurgery with good results. Cobery et al. [17], found that GKS resulted in 48,72 , and $81 \%$ volumetric decreases in three patients treated by subtotal tumor removal, and a $77 \%$ decrease in volume one patient with a recurrent tumor. In a case report by Hara et al. [18], rapid mass shrinkage of a subtotally resected $\mathrm{CN}$ was noticed two months after radiosurgery. Ali Genc et al. [19], in their study comprising of 22 patients with recurrent or residual neurocytomas treated with GKRS has shown that tumor decreased in size in 15 patients, in 6 patients tumor size remained unchanged and in 1 patient size of the tumor increased.
Asymptomatic lateral ventricular tumors have been found incidentally during routine medical checkups. The management of such asymptomatic cases remains controversial. Study done by Ali Genc et al. [19] recommends surgical resection for tumors larger than $3 \mathrm{~cm}$ in diameter. For patients with intraventricular tumors smaller than $3 \mathrm{~cm}$, or for patients with large tumors that are not amenable to surgery and in patients who are at high risk for surgery (i.e., advanced age, other medical conditions), this study recommends a stereotactic biopsy. Once central neurocytoma is confirmed, GKRS can be advised. For symptomatic tumors and asymptomatic but large $(3 \mathrm{~cm})$ lesions, surgery can be curative. However, local recurrence after radiologically shown total resection might occur $[20,21]$. As a result, patients with gross total resection should be closely followed. Current practice is to repeat cranial MRI every three months in the first year, every six months in the second year and yearly thereafter [19]. However, when total resection is not achieved, further treatment should be based on the MIB1 LI of the tumor [19]. Subtotally resected tumors with an MIB1 LI $>2 \%$ should be immediately treated by GKS19. On the other hand, subtotally resected tumors with an $\mathrm{MIB} 1 \mathrm{LI}<2 \%$ may either be treated by GKS or followed until the first sign of progression [19].

\section{Conclusions}

Generally CNs have a favorable prognosis. In cases with MIB 1 LI $>2 \%$, the clinical course can be more aggressive. The primary therapeutic modality remains surgery. However, in asymptomatic patients with tumor $<3 \mathrm{~cm}$, GKRS can be advised after stereotactic biopsy confirmation of neurocytoma. A safe maximal resection confers the best long-term survival and local control. In cases of a subtotal resection, standard external beam radiation can be added or radiation can be delayed until tumor progression occurs. But conventional radiotherapy is associated with long term side effects. So residual tumor or recurrences can be treated with more conformal radiation or focused radiosurgery using Gamma Knife. Various studies have shown effectiveness of GKRS in recurrent or residual neurocytomas. GKRS is an effective and safe alternative therapy for residual or recurrent $\mathrm{CN}$. Further studies are needed to find out the long-term outcomes and optimal GKRS dose for $\mathrm{CN}$.

\section{References}

1. Hassoun J, Gambarelli D, Grisoli F, Pellet W, Salamon G, et al. (1982) Central neurocytoma. An electron-microscopic study of two cases. Acta Neuropathol 56: 151-156.

2. Hassoun J, Söylemezoglu F, Gambarelli D, Figarella-Branger D, von Ammon K, et al. (1993) Central neurocytoma: a synopsis of clinical and histological features. Brain Pathol 3: 297-306.

3. Schild SE, Scheithauer BW, Haddock MG, Schiff D, Burger PC, et al. (1997) Central neurocytomas. Cancer 79: 790-795.

4. Schmidt MH, Gottfried ON, von Koch CS, Chang SM, McDermott MW (2004) Central neurocytoma: a review. J Neurooncol 66: 377-384.

5. Sharma MC, Deb P, Sharma S, Sarkar C (2006) Neurocytoma: a comprehensive review. Neurosurg Rev 29: 270-285.

6. Kim DG, Paek SH, Kim IH, Chi JG, Jung HW, et al. (1997) Central neurocytoma: the role of radiation therapy and long term outcome. Cancer 79: 1995-2002.

7. Leenstra JL, Rodriguez FJ, Frechette CM, Giannini C, Stafford SL, et al. (2007) Central neurocytoma: management recommendations based on a 35-year experience. Int J Radiat Oncol Biol Phys 67: 1145-1154.

8. Bertalanffy A, Roessler K, Koperek O, Gelpi E, Prayer D, et al. (2005) Recurrent central neurocytomas. Cancer 104: 135-142. 
Citation: Shivaramegowda NH, Borkar SA, Garg K, Suri V, Sharma MC, et al. (2014) Central Neurocytomas: A Comprehensive Review with Special Emphasis on the Role of Gamma Knife Stereotactic Radiosurgery. J Hematol Thrombo Dis 3: 140. doi:10.4172/2168-975X. 1000140

Page 5 of 5

9. Brandes AA, Amistà P, Gardiman M, Volpin L, Danieli D, et al. (2000) Chemotherapy in patients with recurrent and progressive central neurocytoma. Cancer 88: 169-174.

10. Dodds D, Nonis J, Mehta M, Rampling R (1997) Central neurocytoma: a clinical study of response to chemotherapy. J Neurooncol 34: 279-283.

11. von Koch CS, Schmidt MH, Uyehara-Lock JH, Berger MS, Chang SM (2003) The role of PCV chemotherapy in the treatment of central neurocytoma: illustration of a case and review of the literature. Surg Neurol 60: 560-565.

12. Paek SH, Han JH, Kim JW, Park CK, Jung HW, et al. (2008) Long-term outcome of conventional radiation therapy for central neurocytoma. J Neurooncol 90: 25-30.

13. Rades D, Schild SE (2006) Value of postoperative stereotactic radiosurgery and conventional radiotherapy for incompletely resected typical neurocytomas. Cancer 106: 1140-1143.

14. Anderson RC, Elder JB, Parsa AT, Issacson SR, Sisti MB (2001) Radiosurgery for the treatment of recurrent central neurocytomas. Neurosurgery 48: 1231-1237.

15. Kim CY, Paek SH, Jeong SS, Chung HT, Han JH, et al. (2007) Gamma knife radiosurgery for central neurocytoma: primary and secondary treatment. Cancer 110: 2276-2284.
16. Tyler-Kabara E, Kondziolka D, Flickinger JC, Lunsford LD (2001) Stereotactic radiosurgery for residual neurocytoma. Report of four cases. J Neurosurg 95: 879-882.

17. Cobery ST, Noren G, Friehs GM, Chougule P, Zheng Z, et al. (2001) Gamma knife surgery for treatment of central neurocytomas. Report of four cases. J Neurosurg 94: 327-330.

18. Hara M, Aoyagi M, Yamamoto M, Maehara T, Takada Y, et al. (2003) Rapid shrinkage of remnant central neurocytoma after gamma knife radiosurgery: a case report. J Neurooncol 62: 269-273.

19. Genc A, Bozkurt SU, Karabagli P, Seker A, Bayri Y, et al. (2011) Gamma knife radiosurgery for cranial neurocytomas. J Neurooncol 105: 647-657.

20. Choudhari KA, Kaliaperumal C, Jain A, Sarkar C, Soo MY, et al. (2009) Central neurocytoma: a multi-disciplinary review. Br J Neurosurg 23: 585-595.

21. Pollock BE, Stafford SL (2001) Stereotactic radiosurgery for recurrent central neurocytoma: case report. Neurosurgery 48: 441-443. 